\title{
The impact of type of Learning Disability and perceived social support on manifest anxiety in children
}

\author{
Mansi Purohit ${ }^{1}$ \\ ${ }^{1}$ Post graduate student, Department of Psychology, Maniben Nanavati Women's College, Mumbai. \\ E-mail-purohitmansi10@gmail.com
}

\begin{abstract}
Background : Learning disability is an invisible disability with little physical manifestations other than problems in the academic arena. Children with LD often have anxiety due to poor academic support, harsh parenting and parental unawareness about the condition. Schools, teachers and peers too may not provide at times an environment suitable for their growth. This study was thus undertaken to study the effects of perceived social support on manifest anxiety in children with learning disability.

Methodology : Data were conducted using self - report survey from 80 children with learning disability (39 single learning disability \& 41 multiple learning disabilities). The sample consisted of children with learning disability aged between 11-16 years. These participants were selected by using convenience sampling method and by looking at their learning disability certificates from various hospitals, institutes and NGOs. The Multidimensional Scale of Perceived Social Support and the Revised Children's Manifest Anxiety Scale was used as assessment measures.

Results : In the multiple LD group, the mean score of 19.64 ( $\mathrm{SD}=5.95)$ was highest for low perceived social support, followed by $14.07(\mathrm{SD}=5.16)$ for moderate social support and $10.23(\mathrm{SD}=6.50)$ for high social support whereas in the single LD the mean score of $13.62(\mathrm{SD}=6.62)$ was highest for moderate perceived social support, followed by $12.15(\mathrm{SD}=7.61)$ for low perceived social support and $9(\mathrm{SD}=8.85)$ for high perceived social support. The total mean of $14.76(\mathrm{SD}=6.93)$ for multiple $\mathrm{LD}$ was higher than the total mean of $11.59(\mathrm{SD}=7.79)$ for single $\mathrm{LD}$. There was a significant difference in the manifest anxiety experienced by the children in both groups $(p<0.05)$. The anxiety between children who experienced different levels of social support was also statistically significant $(\mathrm{p}<0.05)$.

Conclusions : Children diagnosed with multiple learning disabilities appear to have significantly higher manifest anxiety as compared to children with single learning disability. The level of social support experienced by the child also impacts their manifest anxiety with in an inverse relationship. But the two do not interact to affect the overall anxiety that the child experiences.
\end{abstract}

Keywords: children, learning disability, perceived social support, manifest anxiety.

\section{INTRODUCTION}

The National Joint Committee on Learning Disabilities [1] have defined learning disabilities as a general term that refers to a heterogeneous group of disorders manifested by significant difficulties in the acquisition and use of listening, speaking, writing, reasoning or mathematical skills. Learning is acquisition of new knowledge, skills or attitude. Children during their early years of development learn to understand the spoken language first and then learn to speak. Subsequently during the school years learn to read, write and do arithmetic according to their age and intellectual capacity. But some children may not be able to learn one or more of these skills as per their age and intellectual capacity [2]. Manifest anxiety can be defined as anxiety which manifests itself without any underlying 
psychological problem is otherwise known as manifest anxiety. It is the theory that anxiety is fuelled by underlying emotional conflict and repressed feelings [3].

\section{LEARNING DISABILITY AND ANXIETY}

A study on students with learning disability has demonstrated that dyslexic students had higher levels of state anxiety and elevated levels of academic and social, but not appearance anxiety. This anxiety can be present in both academic tasks and many social situations [4]. In a meta analysis on on learning disabilities and anxiety it was noted that students with learning disability had higher mean scores on measures of anxiety than did non-learning disability students. It also indicated that the overall effect size was statistically significant although substantial heterogeneity of results was found [5].

In a study to examine the levels of mathematics and statistics anxiety and also to further examine general mental health amongst undergraduate students with dyslexia, results showed that students with dyslexia had higher levels of mathematics anxiety as compared to those without dyslexia but it was observed that statistics anxiety and general mental health were comparable for both reading ability groups. It was also found that in terms of coping strategies undergraduates with dyslexia tended to use planning-based strategies and seek instrumental support more frequently than those without dyslexia. Further it showed that higher mathematics anxiety was associated with having a dyslexia diagnosis, greater levels of worrying, denial and seeking instrumental support and less use of the positive reinterpretation coping strategy. By contrast statistics anxiety was not predicted by dyslexia diagnosis but it was instead predicted by overall worrying and the use of denial and emotion focused coping strategies [6].

Depression and anxiety are frequently comorbid and researchers have proposed a separate diagnosis of anxious depression [7]. Those with comorbid anxiety-depression experience (1) greater symptom severity, (2) more severe role impairment, (3) increased help-seeking behavior, and (4) higher incidence of suicide, when compared to those with a single diagnosis of depression or anxiety [8]. In a research to study anxiety and depression in children with non verbal learning disabilities, reading disabilities or typical development, results revealed that both non learning disability and reading disability children reported experiencing more generalized and social anxiety than typical development and further it showed that the non learning disability children reported more severe anxiety about school and separation than typical development however the children with reading disability had worse depressive symptoms than those with non learning disability or typical development [9].

Severity and risk status for anxiety and depression have been studied in relation to coping skills. This research was performed on 130 Mexican school children with learning disabilities (LD) and 130 school children without learning disabilities. It was also found that there was no statistically significant difference for coping skills. Results support the idea that there is an increased awareness of comorbid depression and anxiety among students with learning disability and a need to promote early identification and intervention in schools [10]. Many studies have demonstrated that anxiety and depression levels are high in children with all forms of learning disability [11-12]. Individuals with dyslexia are at an increased risk for anxiety disorders generalized anxiety disorder, stress disorders, panic disorder [13].

\section{LEARNING DISABILITY AND SOCIAL SUPPORT}

Social support has been defined as verbal and non verbal communication between recipients and their providers that reduces uncertainty about the situation, the self, the other or the relationships, and the functions to enhance a perception of personal control in one's life experience [14]. Martienz conducted a cross-sectional study to examine the perceptions of social support reported by middle-school students with multiple learning disabilities (LD) (reading \& math) in inclusive settings. Results revealed that learning disability type explained $21 \%(\mathrm{p}<.001)$ of the variance in perceptions of parent, classmate and friend support. It also revealed that students with multiple LD (RD \& MD) reported the lowest perceived social support on these dependent variables [15].

Researchers conducted a qualitative study to explore the lived experiences of perceived support by Iranian mothers who have children with learning disability. In this 
study 12 open interviews with six mothers of learning-disabled children (7-12 years of age) were audiotaperecorded with participants consent. The results indicated that perceived support by Iranian mothers who have children with LD has been insufficient. Two main themes emerged from the narrations: being in the light and being in the shade of support [16]. Norah has described the importance of social cohesion, social support and emotional support, not only upon acceptance of disability but also throughout life as necessary [17].

Research suggests that parental support may be the most important and universal variable related to the development of social competence and wellbeing during adolescence. Various studies indicate that when adolescents perceived their parents as supportive, they have more positive mental health [18]. Various studies have also shown a negative association between perceived parental support and adolescents' depressive symptoms [19-20].

A study to find out the mediational effect of emotional experience with dyslexia (emotions stemming from living with an often misunderstood and stereotyped learning difficulty) that may account for the empirical link between perceived family support and self-esteem revealed that emotional experience with dyslexia mediated the relationship between perceived family support and selfesteem across the entire sample and in early and middle adulthood and mediational effect was strongest in early adulthood [21]. In a study to investigate the relationship between self-perception of a learning disability (SPLD), self-concept and social support, results revealed that children with less negative perceptions of their learning disability had higher math achievement scores and they perceived more positive global self-concept, more intellectual and behavioral competence and more social acceptance. These children also felt more support from their parents and classmates [22].

\section{METHODOLOGY}

Self report data were collected from children with learning disability (both single learning disability and multiple learning disabilities) who were between the age group of 11 to 16 years. These participants were selected by looking at their diagnosis of learning disability certificates from various institutes, hospitals and NGOs. Children with learning disability who were willing to participate administered a consent form, read a brief instruction and description of the study and completed a paper and pencil survey. The researcher was present to help the participants to answer questions if they had any doubts.This study was a $2 \times 3$ between subjects design, as the independent variable: type of learning disability has two levels (single and multiple learning disabilities) and perceived social support has three levels (high, moderate and low). After data was collected a Shapiro-Wilk test of normality and Levene's test of homogeneity was conducted to examine the approximate normality of the data and also to verify the equality of the variance in the samples. Since the data were normally distributed and also the variances were equal the researcher decided to do parametric test. Therefore, a two-way between subjects analysis of variance (ANOVA) was conducted to compare the impact of type of learning disability and perceived social support on manifest anxiety in children. After analysis of the variance Tukey's honest significance of difference test was conducted to compare all the possible pairs of group means (i.e. each group to every other group) to find out which groups are different. This analysis of the data were then coded and entered into statistical software by a team of trained research assistants. Data coding and entry were verified to minimize error. Verified data were then imported to SPSS version 22.0 and Vassar Stats for Windows 9.

Data were conducted using self - report survey from 80 children with learning disability (39 single learning disability \& 41 multiple learning disabilities). The sample consisted of children with learning disability aged between 11-16 years. These participants were selected by using convenience sampling method and by looking at their learning disability certificates from various hospitals, institutes and NGOs.

Standard fact sheet items were used to measure the demographic characteristics of the sample. Reliable and valid measures used in previous studies were used to measure the variables in the study (as outlined below). 


\section{MULTIDIMENSIONAL SCALE OF PERCEIVED SOCIAL SUPPORT (MSPSS)}

In order to assess perceived social support in learning disability children, a multidimensional scale of perceived social support (MSPSS) [23] was used. It has 12 items assessing three sources of support: family, friends, and significant other. Items were rated on a 7-point Likert -scale ranging from (1-very strongly disagree, 2-strongly disagree, 3- mildly disagree, 4- Neutral, 5- Mildly agree, 6- Strongly agree, 7-very strongly agree).The sample items include: a. There is a special person who is around when I am in need. $\mathrm{b}$. My family really tries to help me. c. My friends really try to help me. This scale was used to measure perceived support from family, friends, and a significant other, or global perceived support. The samples were classified with the ranges between 12-48 having low perceived social support, 49-68 having moderate perceived social support and 69-84 high having perceived social support. The validity of total scale are excellent (Cronbach's alphas $=0.85$ to 0.91 ). In addition, the scale have demonstrated strong test-retest reliability over a 2 to 3 month interval ( $r=0.72$ to 0.85 ). Validity has been established through the negative association of scores on the MSPSS with scores on measures of depression.

\section{REVISED CHILDREN'S MANIFEST ANXIETY SCALE (RCMAS)}

In order to assess manifest anxiety in learning disability children, revised children's manifest anxiety scale (RCMAS) [24] was used. It is a 37-item self-report inventory used to measure anxiety in children, for clinical purposes (diagnosis and treatment evaluation), educational settings, and for research purposes. The RCMAS consists of 28 Anxiety items and 9 Lie (social desirability) items. Each item was purported to embody a feeling or action that reflects an aspect of anxiety, hence the subtitle, "What I think and Feel".

\section{RESULTS}

In the multiple LD group, the mean score of $19.64(\mathrm{SD}=5.95)$ was highest for low perceived social support, followed by $14.07(\mathrm{SD}=5.16)$ for moderate social support and $10.23(\mathrm{SD}=6.50)$ for high social support whereas in the single $\mathrm{LD}$ the mean score of $13.62(\mathrm{SD}=6.62)$ was highest for moderate perceived social support, followed by $12.15(\mathrm{SD}=7.61)$ for low perceived social support and 9 $(\mathrm{SD}=8.85)$ for high perceived social support. The total mean of $14.76(\mathrm{SD}=6.93)$ for multiple $\mathrm{LD}$ was higher than the total mean of $11.59(\mathrm{SD}=7.79)$ for single $\mathrm{LD}$. The total mean of $16.04(\mathrm{SD}=7.68)$ was highest for low perceived social support, followed by moderate perceived social support with the total mean of $13.85(\mathrm{SD}=5.80)$ and high perceived social support with the total mean of $9.62(\mathrm{SD}=7.63)$ respectively.

Before carrying out the inferential statistics, the researcher undertook appropriate steps to account for the unequal sample sizes. Unequal sample sizes can cause specific problems for instance, precision in computation of means, violations of assumptions, unequal variances, and finally determining accurately the level at which to reject the null hypothesis. Hence, the researcher reduced 11 samples out of 25 samples from low perceived social support and five samples out of 19 samples from moderate perceived social support from the data of children's with multiple learning disabilities. This reduction of the data was done randomly by removing all the extreme outliers in the scores. Also the researcher substituted single mean to each of low perceived social support and moderate social support in the data of children's with single learning disability.

The ANOVA was then computed to know if the mean differences between the groups indicated a statistically significant result and if there was an interaction between the type of LD and the child's perception of social support. According to the results of Table 1, there is a significant difference in the manifest anxiety experienced by the children in both groups. The anxiety between children who experienced different levels of social support is also statistically significant. However computation of Tukey's HSD indicated that there is no significant interaction between type of disability and level of social support perceived $(\mathrm{F}(2,74)=2.11<7.79,9.28)$. 
Table 1: ANOVA calculations

\begin{tabular}{|llllll|}
\hline Source & $\begin{array}{l}\text { Sum of } \\
\text { Squares }\end{array}$ & df & $\begin{array}{l}\text { Mean } \\
\text { Squares }\end{array}$ & F & Sig. \\
\hline Type of LD & 186.87 & 1 & 186.87 & 3.97 & 0.05 \\
\hline $\begin{array}{l}\text { Perceived Social } \\
\text { Support }\end{array}$ & 546.66 & 2 & 273.33 & 5.81 & 0.005 \\
\hline $\begin{array}{l}\text { Type of LD * } \\
\text { Perceived Social } \\
\text { Support }\end{array}$ & 198.04 & 2 & 99.02 & 2.11 & 0.128 \\
\hline Error & 3479.22 & 74 & 47.02 & & \\
\hline Total & 4431.39 & 79 & & & \\
\hline
\end{tabular}

Summarizing the results, it can be said that children diagnosed with multiple learning disabilities were found to have significantly higher manifest anxiety as compared to children with single learning disability. It was also found that children with learning disability having low perceived social support were found to have significantly highest manifest anxiety followed by children having moderate perceived social support and high perceived social support. Lastly, it was found that there was no impact of the interaction between the type of learning disability (single and multiple) and perceived social support (high, moderate, low) on the manifest anxiety in children. The manifest anxiety in children with single learning disability was found to be highest among moderate perceived social support followed by low perceived social support and high perceived social support whereas in children with multiple learning disabilities the manifest anxiety was highest among low perceived social support, followed by moderate perceived social support and high perceived social support. However, it was not significant.

\section{DISCUSSION}

Researchers have found that children with multiple LD (RD + MD) reported the lowest perceived social support on the dependent variables as compared to students with single learning disability [25]. In the children with single LD the manifest anxiety mean score was highest for moderate perceived social support, followed by low perceived social support and high perceived social support. Therefore, it can be concluded that the manifest anxiety was high for low perceived social support in children with multiple learning disabilities but this interaction was not found for the children with single learning disability since in them manifest anxiety was high for moderate perceived social support.

The following reasons were assumed for the difference between the manifest anxiety of multiple learning disabilities and single learning disability: Children suffering from multiple learning disabilities must be constantly failing in their academics due to severe deficits in learning abilities which could increase their anxiety levels. Social support served as a "protective" factor to people's vulnerability on the effects of stress on health. The buffering hypothesis, social support serves as a protective layer creating psychological distance with between a person and stressful events. Stress buffering is more likely to be observed as perceived support than for structural or received support [26].

Research showed students with LD perceived themselves as having less social support than did students without LD. Although overall the levels of stress reported by the entire sample were relatively low, students with LD tended to experience slightly higher academic stress than students without LD [27]. This is understandable in view of the intense academic pressure experienced by children generally and by those suffering from LD in particular. For instance, studies confirm that dyslexia has specific risk factors for increased internalizing anxiety and depressive symptoms. The severity of dyslexia and its comborbidity with ADHD, the level of perceived social support and female gender are some of the factors that mostly influence its psychosocial outcomes [28]. 
Parental support is defined as perceiving warmth, concern, encouragement, physical affection, and praise from primary parental figures [29]. The researcher assumes that the children having more than one sibling have high manifest anxiety because the love, warmth, concern, encouragement, physical affection from primary parental figures would be getting divided among all the siblings and therefore sometimes in this kind of environment children may feel aloof and anxious. Also, learning disability children having young sibling have high manifest anxiety may be because the parents at home may be more affectionate and concerned for younger sibling since parents have the mentality that younger children could not take care of their selves as compared to the elder child. Parents should be encouraged to show their love and affection to their offspring, which can serve as a beneficial factor that defends against anxiety symptoms. Also in schools, children should be taught how to recognize their parent's attempts to show warmth and affection. Parenting programs and mental health practitioners can also teach families strategies to promote emotional bonding, family flexibility, and family hardiness.

\section{CONCLUSIONS}

Children diagnosed with multiple learning disabilities appear to have significantly higher manifest anxiety as compared to children with single learning disability. The level of social support experienced by the child also impacts their manifest anxiety with in an inverse relationship. But the two do not interact to affect the overall anxiety that the child experiences. The contracting factor between both types of disability was that in case of single disability, children with moderate social support experienced maximum anxiety, whereas in case of multiple disabilities, the anxiety levels peaked with lowest perception of social support. The ancillary results showed that there was no difference in the means of manifest anxiety of males and females. It was found that LD children having more than one sibling and younger siblings have higher manifest anxiety as compared to the children with elder siblings and no siblings. It was also observed that manifest anxiety was highest at the age of 14 and 15 years and lowest at the age of 11 and 16 years in learning disability children. And finally, it was found that LD children in Standard $10^{\text {th }}, 4^{\text {th }}, 5^{\text {th }}$ and $6^{\text {th }}$ had lowest manifest anxiety and highest in standard $7^{\text {th }}, 8^{\text {th }}$ and $9^{\text {th }}$ respectively.

This research will add to the understanding of the role of type of learning disability (single \& multiple L.D.) and perceived social support in their manifest anxiety. However, certain limitations to the study should be acknowledged. The data used for the analyses were collected through self-report questionnaires and since the population was learning disability there is a possibility that this could have caused problems in reading, understanding and marking the responses specially those children who were diagnosed with reading disability and writing disability. Next, since the fact that the data was collected from the population diagnosed with learning disability the researcher read and explained the questionnaires for some of the participants who were really not able to read and understand the questions in comparison to others. Therefore, this could be confounding because some participants could have understood the questions better as compared to others. Further, the questionnaires were based on the manifest anxiety and their perceptions of social support; it can impact the accuracy of the responses if specific circumstantial events occurred during the time of the questionnaire. For example, if a child had an especially negative or positive interaction with the parents, friends on the day of data collection or due to some reason there manifest anxiety was high or low it could have biased their answers.

From a theoretical standpoint, further researches could be conducted to determine the main causes of higher manifest anxiety of children with multiple learning disabilities. Also research could be conducted to study that which combinations of multiple learning disabilities have a higher manifest anxiety. The findings of this study suggest various implications for educators, mental health counselors, and parents. The schools and institutes can develop various coping strategies and intervention programs to reduce manifest anxiety in children's diagnosed with multiple learning disabilities. Also conduct effective training to overcome their learning disabilities. 


\section{REFERENCES}

1. Fuchs D, Mock D, Morgan PL, Young CL. Responsiveness-to-intervention: Definitions, evidence, and implications for the learning disabilities construct. Learning Disabil Res Pract 2003;18(3):157-71.

2. Karande S, Satam N, Kulkarni M, Sholapurwala R, Chitre A, Shah N. Clinical and psychoeducational profile of children with specific learning disability and co-occurring attention-deficit hyperactivity disorder. Indian J Med Sci 2007;61(12):639-47.

3. Spence JT, Spence KW. The motivational components of manifest anxiety: Drive and drive stimuli. Anxiety Behav 1966:291-326.

4. Carroll JM, Iles JE. An assessment of anxiety levels in dyslexic students in higher education. Br J Educ Psychol 2006;76(3):651-62.

5. Nelson JM, Harwood HR. A meta-analysis of parent and teacher reports of depression among students with learning disabilities: Evidence for the importance of multi-informant assessment. Psychol Schools 2011;48(4):371-84.

6. Hassinger-Das B, Jordan NC, Glutting J, Irwin C, Dyson N. Domain-general mediators of the relation between kindergarten number sense and first-grade mathematics achievement. J Exp Child Psychol 2014;118:78-92.

7. Fava M, Rankin MA, Wright EC, Alpert JE, Nierenberg AA, Pava J, Rosenbaum JF. Anxiety disorders in major depression. Compr Psychiatr 2000;41(2):97-102.

8. McCann BS, Roy-Byrne P. Attention-deficit/hyperactivity disorder and learning disabilities in adults. Sem Clin Neuropsychiatr 2000;5(3):191-7.

9. Kendeou P, Broek P, Helder A, Karlsson J. A cognitive view of reading comprehension: Implications for reading difficulties. Learning Disabil Res Pract 2014;29(1):10-6.

10. Gallegos J, Langley A, Villegas D. Anxiety, Depression, and Coping Skills Among Mexican School Children A Comparison of Students With and Without Learning Disabilities. Learning Disabil Quart 2012;35(1):54-61.

11. Alesi M, Rappo G, Pepi A. Depression, Anxiety at School and Self-Esteem in Children with Learning Disabilities. J Psychol Abnorm Children 2014;3:125.

12. Nelson JM, Gregg N. Depression and anxiety among transitioning adolescents and college students with ADHD, dyslexia, or comorbid ADHD/dyslexia. J Attention Disord 2012;16(3):244-54.

13. Whitehouse AJ, Durkin K, Jaquet E, Ziatas K. Friendship, loneliness and depression in adolescents with Asperger's Syndrome. J Adolescence 2009;32(2):309-22.

14. Alderman MK. Motivation for achievement: Possibilities for teaching and learning. Routledge; 2013.

15. Martínez RS. Social support in inclusive middle schools: Perceptions of youth with learning disabilities. Psychol Schools 2006;43(2):197-209.

16. Kermanshahi SM, Vanaki Z, Ahmadi F, Kazemnejad A, Azadfalah P. Children with learning disabilities: A phenomenological study of the lived experiences of Iranian mothers. Int J Qualitat Stud Health Well-being 2008;3(1):18-26.

17. Hudson B. Making and missing connections: learning disability services and the transition from adolescence to adulthood. Disabil Society 2006;21(1):47-60.

18. Reed GM, Lux JB, Bufka LF, Trask C, Peterson DB, Stark S, Threats TT, Jacobson JW, Hawley JA. Operationalizing the International Classification of Functioning, Disability and Health in Clinical Settings. Rehabil Psychol 2005;50(2):122-31.

19. Plunkett SW, Henry CS, Robinson LC, Behnke A, Falcon III PC. Adolescent perceptions of parental behaviors, adolescent self-esteem, and adolescent depressed mood. J Child Fam Stud 2007;16(6):760-72.

20. Barber C, Mueller CT. Social and self-perceptions of adolescents identified as gifted, learning disabled, and twice-exceptional. Roeper Rev 2011;33(2):109-20.

21. Nalavany BA, Carawan LW, Rennick RA. Psychosocial experiences associated with confirmed and selfidentified dyslexia: A participant-driven concept map of adult perspectives. J Learning Disabil 2011;44(1):6379.

22. Rothman HR, Cosden M. The relationship between self-perception of a learning disability and achievement, self-concept and social support. Learning Disabil Quart 1995;18(3):203-12.

23. Zimet GD, Dahlem NW, Zimet SG, Farley GK. The multidimensional scale of perceived social support. J Personal Assess 1988;52(1):30-41.

24. Reynolds CR, Richmond BO. What I think and feel: A revised measure of children's manifest anxiety. J Abnorm Child Psychol 1978;6(2):271-80.

25. Usher EL, Pajares F. Sources of academic and self-regulatory efficacy beliefs of entering middle school students. Contemp Educ Psychol 2006;31(2):125-41. 
26. Gresham FM, Sugai G, Horner RH. Interpreting outcomes of social skills training for students with highincidence disabilities. Exceptional Child 2001;67(3):331-44.

27. Heiervang E, Stormark KM, Lundervold AJ, Heimann M, Goodman R, Posserud MB, Ullebø AK, Plessen KJ, Bjelland I, Lie SA, Gillberg C. Psychiatric disorders in Norwegian 8-to 10-year-olds: an epidemiological survey of prevalence, risk factors, and service use. J Am Acad Child Adolesc Psychiatry 2007;46(4):438-47.

28. Ryan J. Learning Disabilities in Australian Universities Hidden, Ignored, and Unwelcome. J Learning Disabil 2007;40(5):436-42.

29. Sena JD, Lowe PA, Lee SW. Significant predictors of test anxiety among students with and without learning disabilities. J Learning Disabil 2007;40(4):360-76.

$$
\begin{aligned}
& \text { Acknowledgements - Nil } \\
& \text { Source of Funding - Nil } \\
& \text { Conflict of Interest - Nil }
\end{aligned}
$$

